\title{
Analysis and Joining of Al-Cu Plates Using Friction-Stir Welding Technique
}

\author{
Ahmet Çakan ${ }^{1 *}$, Hatice Atmaca', Mustafa Uğurlu' \\ ${ }^{1}$ Mersin Üniversitesi, Mühendislik Fakültesi, Makine Mühendisliği Bölümü, Mersin, Türkiye \\ Email: ahcakan@mersin.edu.tr, hatmaca@mersin.edu.tr, mustafaugurlu@mersin.edu.tr
}

\begin{abstract}
The scope of the study focused on tool speeds-plate temperatures at joining aluminium alloy and copper plates. The AA7075-T6 aluminium alloy and pure copper were welded using friction-stir welding (FSW) technique. The temperature variations of plates from stirred zone were detected using thermocouples installed at equal distance on both sides of the axis of the pin linear displacement. The temperature distribution in the surroundings of the welded zone was investigated. The effects of tool rotational speeds on plate temperatures were determined using such welding parameters of three tool rotational speeds of 660, 920 and $1500 \mathrm{rpm}$ at a constant welding speed of $32 \mathrm{~mm} / \mathrm{min}$.
\end{abstract}

Keyword: Welding, joining, friction, stir, temperature

\section{INTRODUCTION}

Friction-stir welding is a solid-state welding technique in which plates are joined by mechanical processes. This joining technique is used in the welded joint of aluminium alloys, copper, magnesium, titanium, and many metallic materials except for iron [1-5]. Recent studies show that the method has a potential to be also applied in joining rigid materials such as steel [6]. Since FSW is performed in a solid state without fusion, generally high-quality weld is produced in which crack formation, porosity, oxidation, and other typical welding defects in the traditional fusion welding technique occur less commonly. The process of friction-stir welding is presented in Fig. 1. The workpieces ( $\mathrm{Al}$ and $\mathrm{Cu}$ plate) are placed on a steel plate with the help of a clamping apparatus to prevent horizontal movements during the process and is rigidly detected. The specially designed protruding shoulder tool with a light taper screw with pin rotating at hundreds of rotational speed is slowly immersed in the parting line for the start of the joining process. The pin is immersed in the workpiece until it comes into contact with the workpiece surface of the shoulder. The upper surface of the workpiece and the friction tool shoulder surface generate heat. The increased material temperature under the shoulder reduces the material strength. The pin of the rotating tool ensures that the materials are stirred in the two plates to ensure joining.

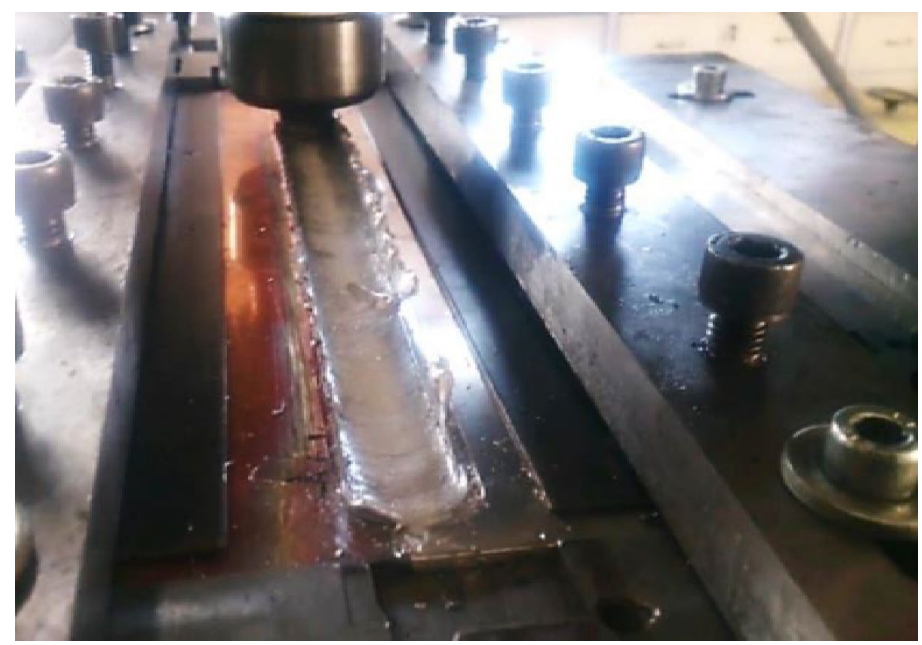

Fig. 1. Performing the FSW procedure on a universal milling machine with a vertical head

One of the key elements in the FSW process is the generation of heat at the tool and workpiece interfaces [7-9]. The heat flow must keep the temperature sufficiently high in the workpiece. In this way, the material reaches softness that will 
allow the pin to stir. However, due to the sufficient heat flow, melting does not occur in the material. The temperature generated by the FSW process can be as high as $80-90 \%$ of the melting temperature of the Al-Cu welded joined material [10]. Therefore, common welding defects and major distortions associated with fusion welding are at a minimum level in FSW joints.

In the FSW process, heat is generated by friction and deformation. Heat is transmitted to both the tool and the workpiece. Factors such as the amount of heat transmitted to the workpiece, the shape of the weld, the quality of the weld, the microstructure of the weld, the residual stress formation, and distortion in the workpiece also determine the success of the FSW process. In welded joint, the amount of heat transmitted to the tool affects the tool capacity and tool life. Inadequate heat leads to the fracturing of the pin part of the tool since it does not provide adequate softening in the material, and leads to cold fusion in the welded region produced [10]. In this study, the effects of the tool rotational speed and welding speed on temperature distribution in the FSW joining of two different materials such as $\mathrm{Cu}$ and $\mathrm{Al}$ were determined.

\section{MATERIAL AND METHOD}

\subsection{Study Material}

The welded joint process was applied to AA 7075-T6 aluminium alloy and (TS-EN-1652) Cu ETP R240 copper plates of $138 \times 300 \times 3 \mathrm{~mm}$ size using the FSW method. The chemical properties of AA 7075-T6 aluminium and (TSEN-1652) Cu ETP R240 copper materials used in the study are presented in Table 1.

Table 1. Chemical Compositions of AA 7075-T6 Aluminium Alloy and (TS-EN-1652) Cu ETP R240 Copper

\begin{tabular}{|c|c|c|c|c|c|c|c|c|c|c|c|c|c|c|}
\hline \multirow{2}{*}{ Material } & \multicolumn{10}{|c|}{ Chemical Composition (\% weight) } \\
\cline { 2 - 23 } & $\mathrm{Si}$ & $\mathrm{Fe}$ & $\mathrm{Cu}$ & $\mathrm{Mn}$ & $\mathrm{Mg}$ & $\mathrm{Cr}$ & $\mathrm{Ni}$ & $\mathrm{O}$ & $\mathrm{Zn}$ & $\mathrm{Ti}$ & $\mathrm{Zr}$ & $\mathrm{Al}$ & $\mathrm{Pb}$ \\
\hline AA7075-T6 & 0.07 & 0.14 & 1.6 & 0.06 & 2.7 & 0.19 & $60 \mathrm{ppm}$ & - & 5.8 & 0.02 & 0.01 & 89.41 & - \\
\hline $\begin{array}{c}\text { (TS-EN-1652) Cu } \\
\text { ETP R240 }\end{array}$ & - & - & 99.900 & - & - & - & - & 0.040 & - & - & - & - & 0.005 \\
\hline
\end{tabular}

\subsection{Tool Material}

H13 tool steel, which is widely used in hot and cold forming processes and has superior properties such as high abrasion resistance, toughness, and susceptibility to machining, was used as a tool material in the FSW joining process. It consists of a tool, pin, shoulder, and a body that carries them over. The pin was conically manufactured with a diameter of 4-6 $\mathrm{mm}$ and a length of $2.7 \mathrm{~mm}$ using the machining method, and then, a screw was drilled on this conical cavity. The shoulder was formed by producing a concavity with a depth of approximately $1.3 \mathrm{~mm}$ from $6 \mathrm{~mm}$ of the body diameter and a distance of $3 \mathrm{~mm}$ from the outer diameter. The tool designed and produced for the purpose of carrying out experimental studies is presented in Fig. 2.

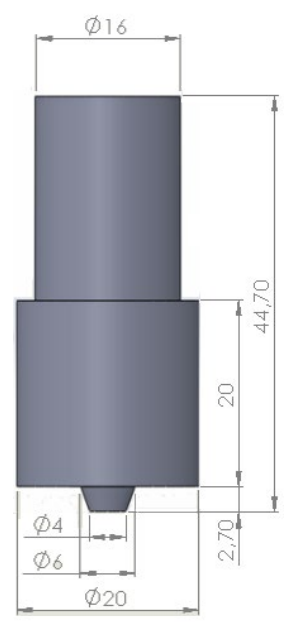

Fig. 2. The tool used in the FSW process

\subsection{Welding Process}

Welded joint was performed in a dry environment at room conditions using the FIRST LC20VGN universal milling machine with the power of $2.8 \mathrm{~kW}$ and a vertical milling head shown in Fig. 1. Three different rotational speeds (660, 920 , and $1500 \mathrm{rpm}$ ) and a constant feed rate of $32 \mathrm{~mm} / \mathrm{min}$ were used in the experiments, and a $1 \mathrm{~mm}$ offset was applied to through the $\mathrm{Al}$ side. 
The milling machine was set at the specified rotational speed and feed rate, and the rotation direction of the tool was set so that pure copper was on the stacking side and AA7075-T6 alloy was on the sweeping side. Once the necessary preliminary preparation was completed, the FSW process consisting of the plunge, waiting, feeding, and withdrawing phases was started.

The penetration of the tool tip, which rotates at the specified rotation with the slow upward movement of the milling table, into the piece was ensured. The upward movement of the table was continued until the shoulder contacted the surface o the workpiece. After the shoulder of the rotating tool of which pin part was immersed in the piece was brought into contact with the base metal, the amount of plunge was adjusted and waited for about 4 minutes, and the progress of the tool along the welding line was ensured at the specified welding speed. The images of the welding process are presented in Fig. 3.

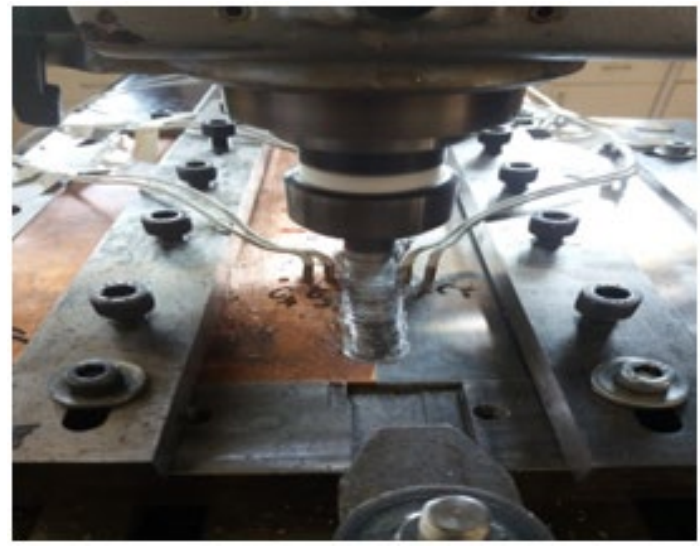

Fig. 3. İmages of the welding process

\subsection{Temperature Measurement}

During the FSW process, the temperature distribution is a function of the heat generated by the friction between the workpiece that is in contact with the tip and shoulder of the tool. The heat generated by the friction effect between the tool and workpiece affects the physical properties of the workpiece and the tool [11]. Using K type thermocouples, commercially obtained from TETCIS company, the temperature values of aluminium and copper plates were determined in the FSW process in which different welding parameters were used. The thermocouples were placed in blind holes 3 $\mathrm{mm}$ in diameter at a distance of approximately $14 \mathrm{~mm}$ and $22 \mathrm{~mm}$ from the welding line to the aluminium and copper sides, as shown in Fig. 4. The blind holes were produced at a depth of approximately $2.5 \mathrm{~mm}$ from the aluminium and copper plate surface to the base. The temperature values obtained from the thermocouples were recorded online using a data logger capable of recording data at intervals of $0.1 \mathrm{~s}$.

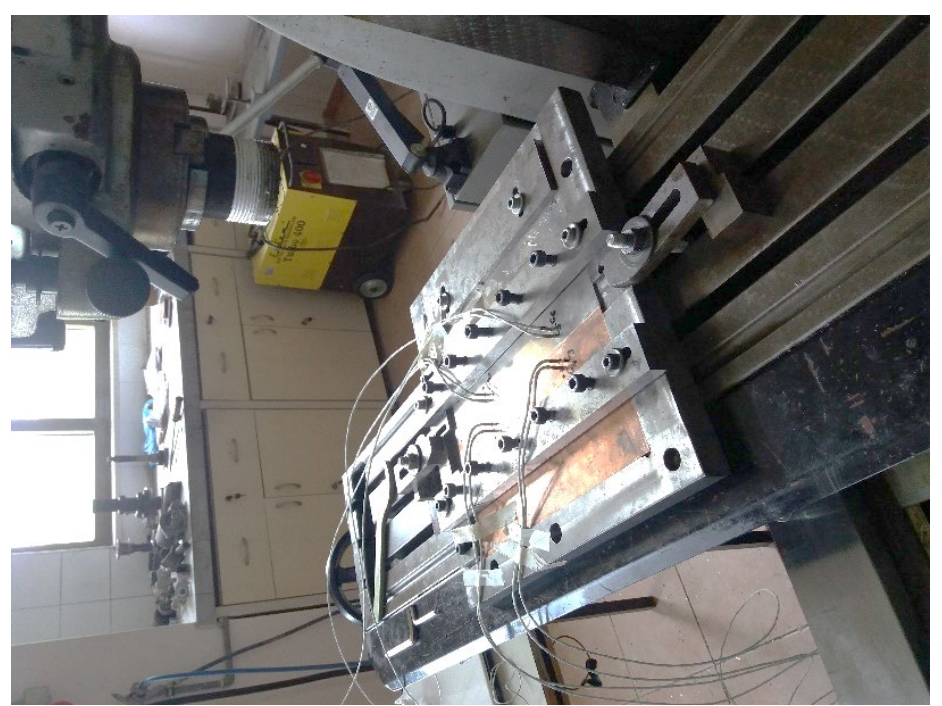

Fig. 4. Placing thermocouples on $\mathrm{Al}-\mathrm{Cu}$ plates in FSW process

\subsection{Heat Generation and Distribution in the Friction-Stir Welding Process}

The energy flow in the workpiece in the FSW process is shown in Fig. 5. In FSW joining, heat generation between metals 
has two causes: (a) intersectional abrasion due to the roughness of the contacting surfaces (b) micro-plastic deformation occurring during the relative movement of the contacting surfaces. All of the friction energy distributed during micro deformations on the surfaces is converted into thermal energy. How the heat generated in this way is distributed depends on the thermal conductivities of the tools and workpieces, thermal capacities, the relative speed, and the intersection area. The friction-related heat generation is theoretically calculated either by the Coulomb friction or constant shear models $[12,13]$.

The shear stress in the constant shear model is calculated by using the following equation:

$$
\tau=m \sigma_{y}
$$

Here, $\sigma_{y}$ is the yield stress of the material, and $m$ is the proportionality constant. $m=1$ is used in the adherence condition, $m=0$ in the release condition. In the constant shear model, the workpiece surface in contact with the tool is assumed to behave like a material with the constant shear stress. The maximum possible shear stress is equal to the yield stress and is equivalent to the case when the workpiece adheres to the tool surface and deforms at the bottom surface (i.e. $m=1$ ) [13].
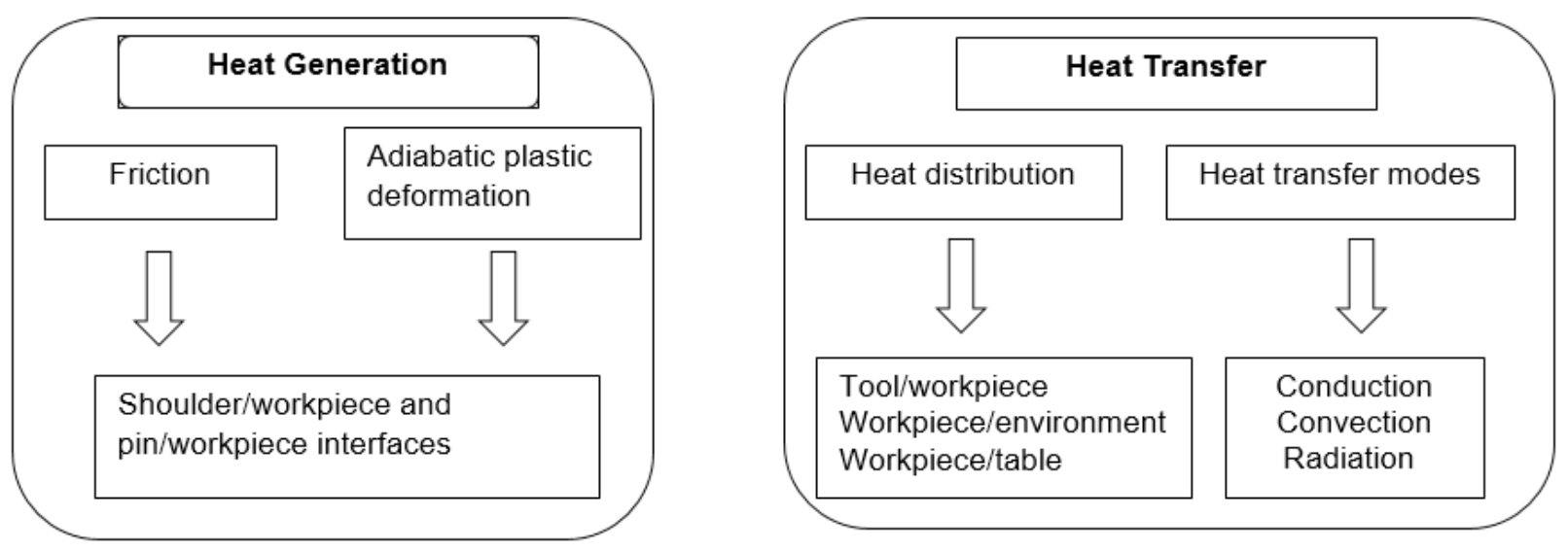

Fig. 5. The thermal energy generated and distributed during FSW process [13].

The heats generated in certain parts of the tool-workpiece interface during welding are separated from each other as follows. Q1: Heat generated on the shoulder of the tool, Q2: Heat generated on the lateral surface of the pin, Q3: Heat generated at the tip of the pin. The different surface areas of the tool are presented in Fig. 6.
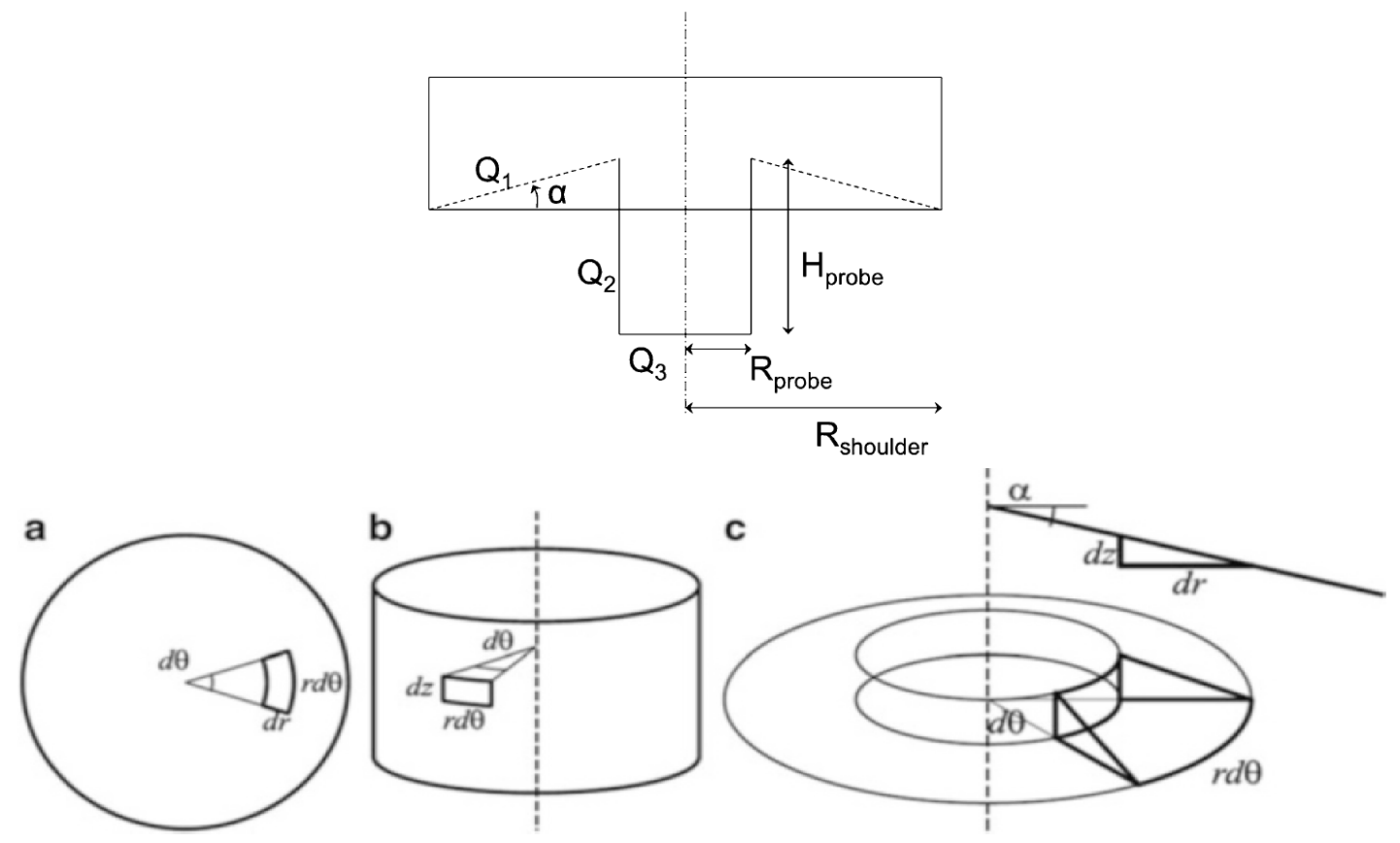

Fig. 6. The tool's dimensions and the schema of different surface areas (a) the pin end, (b) the cylindrical lateral surface of the pin, (c) the endless small slices representing the conical surface and regions on the shoulder [13]. 
For each of the different regions in the tool-workpiece interface, the general heat generation equation is as follows [13]:

$$
d Q=\omega r d F
$$

Here, $d Q$ is the heat generated at a unit time, $d F$ is the force affecting the surface at $r$ distance from the tool axis, and $\omega$ is the angular velocity of the tool. Accordingly, the heat expressions generated on the shoulder, pin surface, and pin end of the tool, respectively, are solved in the following equations in the differential form and integrated [13]:

$$
\begin{aligned}
& d Q_{1}=\omega r^{2} \tau_{\text {shear }}(1+\tan \alpha) d r d \theta \\
& Q_{1}=\frac{2}{3} \pi(1+\tan \alpha) \omega \tau_{\text {shear }}\left(R_{\text {shoulder }}^{3}-R_{\text {pin }}^{3}\right) \\
& d Q_{2}=\omega R_{\text {pin }}^{2} \tau_{\text {shear }} d \theta d z \\
& Q_{2}=2 \pi \tau_{\text {shear }} R_{\text {pin }}^{2} \omega H_{\text {pin }} \\
& d Q_{3}=\omega r^{2} \tau_{\text {shear }} d \theta d r \\
& Q_{3}=\frac{2}{3} \pi \tau_{\text {shear }} R_{\text {pin }}^{3} \omega
\end{aligned}
$$

The local plastic deformation occurring in the workpiece volume also provides a significant contribution to the heat transferred to the weld zone. The amount of plastic deformation energy, which can vary between 80 and $100 \%$, is distributed as heat and the remaining part is stored in the microstructure. Numerical simulations predict that the heat coming from the volumetric plastic deformation may be between $2 \%$ and $20 \%$, although there are no experimental data on the contribution of this energy to FSW.

The transfer directions and mechanisms of the heat generated between the workpiece and the tool during FSW are shown in Fig. 7 [12].

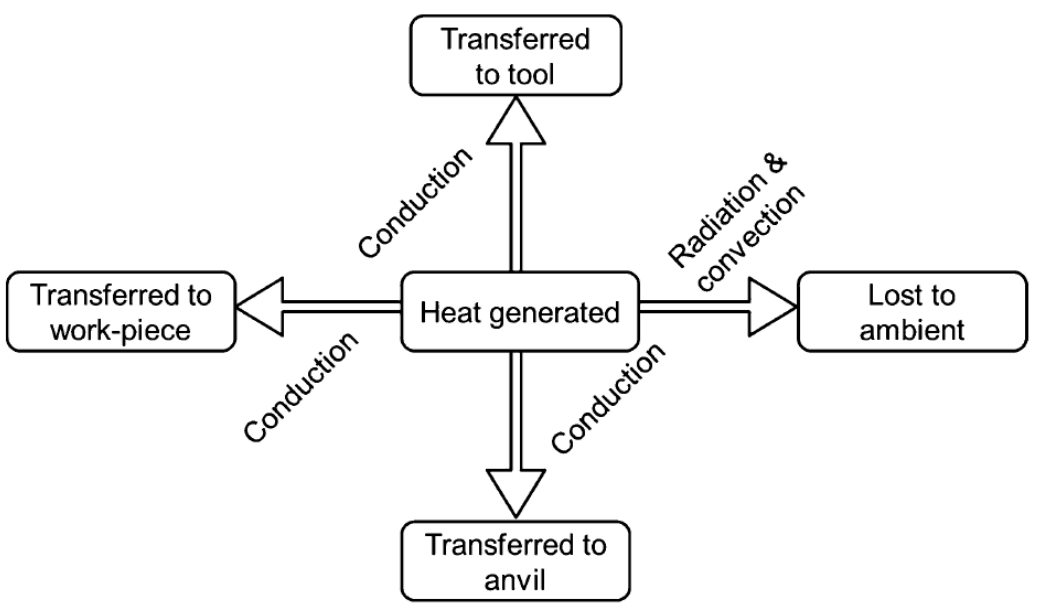

Fig. 7. Transfer mechanisms of the heat generated during the friction stir process [12].

\subsection{Assumptions used in the analyses}

The effect of heat originating from plastic deformation is neglected in the calculation of heat generation. The constant shear model is used to calculate the friction-related heat generation. It is accepted that the tool and the workpiece are adhered during welding, therefore, the proportionality constant is taken as $m=1$. In the calculations, the yield stress of 460 MPa of the AA7075-T6 aluminium alloy with a lower melting temperature was used as the yield stress [14]. Since the cone angle of the tool shoulder is too small, it was neglected in the calculations. Due to the fact that many factors such as friction, shear, adhesion, stirring of materials, transfer of material, heat generation, heat transfer, etc. are effective in the welding stir zone in FSW and that the rotating tool moves to the cold region of the material at a certain speed (welding speed) along the welding line, the variation of shear stress and yield stress with temperature is neglected. During the process, the angular velocity of the pin is assumed to be constant. The effect of the feed rate of the tool along the weld on the heat generation is neglected. It is assumed that the heat transferred to the workpiece by conduction is one-dimensional and there is no internal heat generation in the region where the thermocouples are placed. 


\section{FINDINGS AND CONCLUSION}

The amounts of heat generated at the tool shoulder, pin surface, and pin top at different revolutions are presented in Table 2.

Table 2. Friction-related heat generation values

\begin{tabular}{|c|c|c|c|c|}
\hline$(\mathrm{rpm})$ & $(\mathrm{kW})$ & $(\mathrm{kW})$ & $(\mathrm{kW})$ & $(\mathrm{kW})$ \\
\hline 660 & 65.55 & 3.371 & 1.040 & 69.96 \\
\hline 920 & 91.37 & 4.699 & 1.450 & 97.52 \\
\hline 1500 & 149.0 & 7.661 & 2.365 & 159.0 \\
\hline
\end{tabular}

The heat generated on the tool shoulder has a rate of approximately $94 \%$ in the friction-related heat generation. Heat generation on the tool shoulder, pin surface, and pin top increases linearly with the number of revolutions.

The workpiece made of $\mathrm{Al}-\mathrm{Cu}$ plates was pre-heated by a 4-minute wait from its contact with the shoulder workpiece surface prior to the feed rate of the tool required for welded joint. The maximum temperature values were obtained from the thermocouples close to the joining line. During the process, heat radiation affects the quality of the weld. If the temperature generated by the friction heat around the weld line is low, it will prevent the tool from stirring, resulting in the fracturing of the pin part of the tool. The high temperature facilitates stirring of the tool by allowing the metal flow. However, the extremely high temperature can cause the materials to smear to the tool pin and shoulder and create a large grain structure. In experimental studies, the high temperature was reached in the region near the weld centre line of Al plate with the parameters such as the rotational speed of $1500 \mathrm{rpm}$ and the welding speed of $32 \mathrm{~mm} / \mathrm{min}$ (Fig. 10). At the beginning of the FSW process, both the tool and Al-Cu plates are at the room temperature. When the rotating tool is slowly immersed in the workpiece, it produces chips similar to those of machining because the material is too cold to flow. However, this led to an increase in the temperature of the tool and plates, and in this way, the softening of the workpiece was started. The temperature increase rate depends on the rate of tool immersion (penetration) into the workpiece. The process of immersing the tool into the workpiece continues until the tool shoulder is in contact with the workpiece surface. In this phase, the shoulder and pin surfaces of the tool contribute to the friction heat generation and make the workpiece reach the critical temperature for the plastic flow. This time interval is known as the waiting period. After the waiting period was completed, the tool was given a feed rate, and it was ensured that it proceeded along the welding line. The temperature values obtained from the thermocouples previously placed on the Al-Cu plates as the temperature values produced by the friction heat in the welding process are at a certain distance to the welding line are presented in Figs. 8-10.

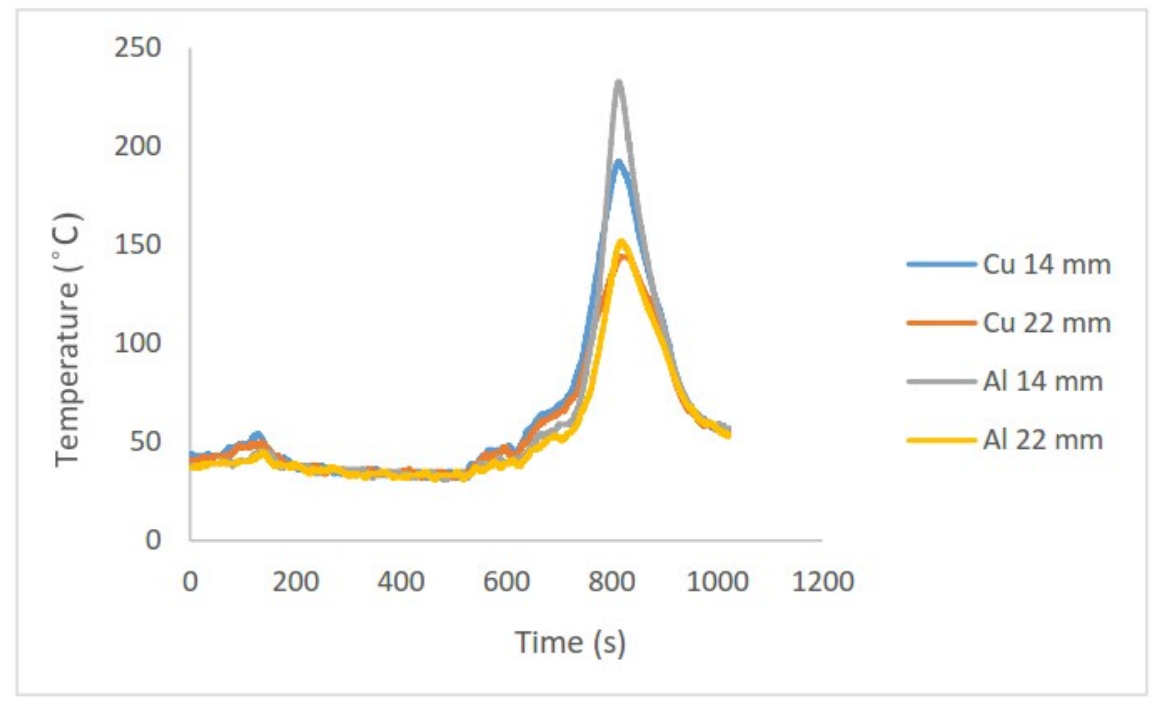

Fig. 8. Temperatures evaluation at the thermocuples located in the workpiece (rotational of $660 \mathrm{rpm}$ and feed rate of $32 \mathrm{~mm} / \mathrm{min}$ )

The highest temperature value was obtained from the thermocouple placed on the $\mathrm{Al}$ plate at a distance of $14 \mathrm{~mm}$ to the welding line at approximately $300^{\circ} \mathrm{C}$ (Fig. 10). This temperature value obtained is considerably lower than the melting temperature of $\mathrm{Al}$ material. 


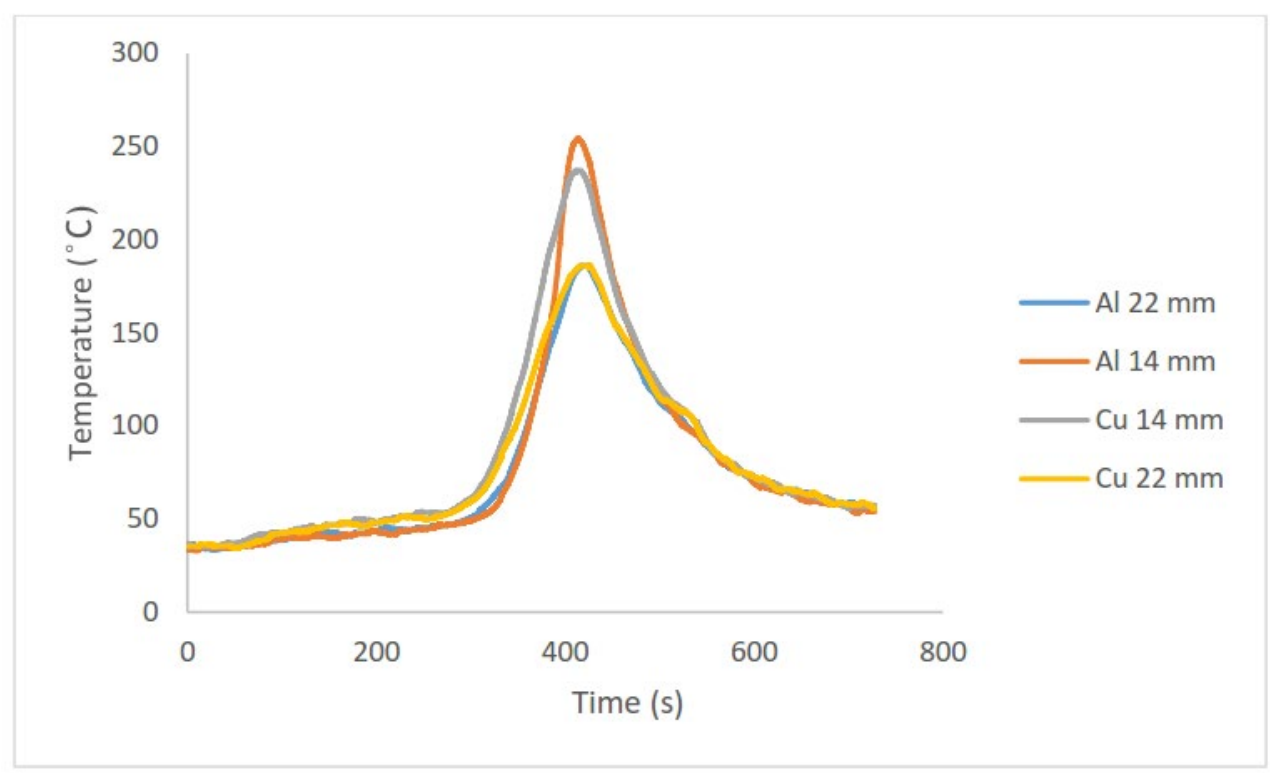

Fig. 9. Temperatures evaluation at the thermocouples located in the workpiece (rotational speed of $920 \mathrm{rpm}$ and feed rate of $32 \mathrm{~mm} / \mathrm{min}$ )

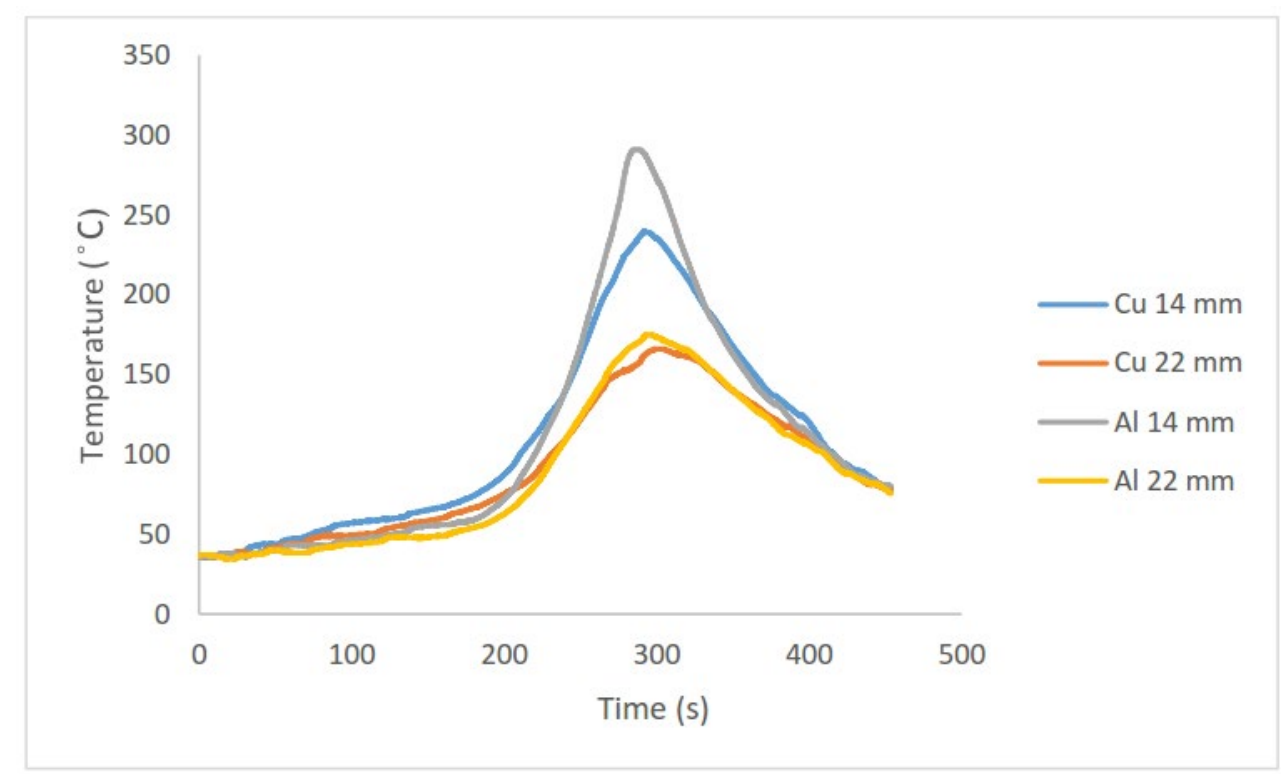

Fig. 10. Temperatures evoluation at the thermocouples located in the workpiece (rotational speed of $1500 \mathrm{rpm}$ and $32 \mathrm{~mm} /$ min constant welding speed)

\section{ACKNOWLEDGEMENT}

This study was supported by Mersin University, Scientific Research Projects (BAP) project numbered "2017-1AP4-2189”. We would like to thank it for its financial support for the study.

\section{REFERENCES}

[1] Khan N.Z., Siddiquee A.N., Khan Z.A. and Mukhopadhyay A.K., (2017) "Mechanical and microstructural behavior of friction stir welded similar and dissimilar sheets of AA2219 and AA7475 aluminium alloys", Journal of Alloys and Compounds,Vol: 695, pp.2902-2908.

[2] Cam G.,Gucluer S., Cakan A. and Serindag H.T., (2009) "Mechanical properties of friction stirbutt-welded Al-5086 H32 plate", Materialwissenschaft und Werkstofftech, Vol:40, pp.638-642.

[3] Shojaei Zoeram A., Mousavi Anidjan S.H., Jafarianb H.R. and Bhattacharjee T., (2017) "Welding parameters analysis and microstructural evolution of dissimilar joints in $\mathrm{Al} /$ Bronze processed by friction stir welding and their effect on engineering tensile behavior", Materials Science \& Engineering A, Vol:687, pp.288-297.

[4] Mehta K. P. and Badheka V. J., (2016) "A review on dissimilar friction stir welding of copper to aluminum: process, properties, and variants", Materials and Manufacturing Processes, Vol:31, pp.233-254.

[5] Dorbane A., Mansoor B., Ayoub G., Shunmugasamy V.C. and Imad A., (2016) "Mechanical, microstructural and fracture 
properties of dissimilar welds produced by friction stir welding of AZ31B and Al6061”, Materials Science \& Engineering A, Vol:651, pp.720-733.

[6] Lee W.B., Schmuecker M., Mercardo U.A., Biallas G. and Jung S.B., (2006) “Interfacial reaction in steel-aluminum joints made by friction stir welding", Scripta Materialia, Vol:55, pp.355-358.

[7] Lambrakos S.G., Fonda R.W., Milewski J.O. and Mitchell J.E., (2003) "Analysis of friction stir welds using thermocouple measurements", Science and Technology of Welding and Joining, Vol:8(5), pp.385-390.

[8] Al-Roubaiy A. O., Nabat S. M. and Batako A.D. L., (2014) "Experimental and theoretical analysis of friction stir welding of $\mathrm{Al}-\mathrm{Cu}$ joints", The International Journal of Advanced Manufacturing Technology, Vol:71, pp.1631-1642.

[9] Song M. and KovacevicR., (2003) “Thermal modeling of friction stirwelding in a moving coordinate system and its validation", International Journal of Machine Tools and Manufacture, Vol:43, pp.605-615.

[10] Chao Y. J., Asme M., X. Qi. and Tang W., (2003) "Heat Transfer in Friction Stir Welding-Experimental and Numerical Studies”, Journal of Manufacturing Science and Engineering, Vol:125, pp.138-145.

[11] Verma S, Meenu, Misra J P., "Study on temperature distribution during Friction Stir Welding of 6082 aluminum alloy”, 5th International Conference of Materials Processing and Characterization : Materials Today. Proceedings; 2017; p. 1350-1356.

[12] Mishra R., De P.S., and Kumar N., "Friction Stir Welding and Processing: Science and Engineering", Springer International Publishing, Switzerland, 2014; pp.13-58.

[13] Durdanovic M. B., Mijajlovic M. M., Milcic D. S. and Stamenkovic D. S., (2009) «Heat generation during friction stir welding process», Tribology in Industry, Vol:31, pp.8-14.

[14] http://incialuminyum.com/mekanik-ozellikler.asp, 30/09/2017. 